\title{
EQUATIONS FOR GAMMA-RAY ATTENUATION SYSTEMS WITH BEAM DIRECTED VERTICALLY, ALONG GRAVITATIONAL FIELD
}

Elimoel A. Elias ${ }^{1}$

\section{ABSTRACT}

One common feature in most systems of gamma-ray attenuation (GRA) is that the gamma beam is located horizontally. In this theoretical work, we show some possible advantages of employing a vertical beam, in two situations where the sample is affected by gravity: (i) particle-size analysis by GRA; and (ii) determination of GRA coefficients of soils. We derive appropriate equations to such situations.

Key words: calibration constants, particle size distribution, transmission, absorption, automation, radiation.

\section{RESUMO}

\section{EQUAÇÕES PARA SISTEMAS DE ATENUAÇÃO DE RADIA- ÇÃO GAMA COM FEIXE DIRIGIDO VERTICALMENTE, AO LONGO DO CAMPO GRAVITACIONAL}

Uma característica comum na maioria dos sistemas de atenuação de radiação gama é que o feixe gama é disposto horizontalmente. Neste trabalho teórico, são mostradas algumas possíveis vantagens de empregar-se um feixe vertical, em duas situações onde a amostra é afetada pela gravidade: (i) análise granulométrica por atenuação da radiação gama; e (ii) determinação de coeficientes de atenuação da radiação gama de solos. São aqui deduzidas equações apropriadas para estas situações.

Palavras-chave: constantes de calibração, distribuição de tamanho de partículas, transmissão, absorção, automatização, raios gama.

1. Dep. de Ciências Exatas, Esalq, USP, Piracicaba. 


\section{INTRODUCTION}

Systems of gamma-ray attenuation (GRA) have been widely reported. One common feature in most systems, or perhaps all of them, is that the gamma beam is directed horizontally, i.e., directed perpendicularly in relation to the gravitational field. This should not make any difference in terms of experimental results, if the phenomenon studied is not related to gravity. It should make a practical difference in terms of laboratory work: it would be easier to work with a horizontal GRA system than with a vertical system. However, some phenomena studied are indeed related to gravity. One example is application of GRA to particle-size analysis (PSA), because it is based on sedimentation. Another example is the measurement of GRA coefficients of soils, because the soil sample is generally oven-dried, sieved, and packed inside a plastic box; and the process of packing is affected by gravity, so stratification may occur in some degree. In this theoretical study, we show some possible advantages of employing a vertical GRA system in such situations, i.e., a system where the gamma beam is directed along the gravitational field.

\section{SIMPLIFIED EQUATION FOR PSA BY GRA}

Many studies have reported PSA by GRA; e.g., Ross (1959), Karsten and Kotzé (1984), Vaz et al. (1992, 1999), Oliveira et al. (1997), Elias et al. (1999a, b), Naime et al. (2001), and Elias (2004). One problem not yet solved was stated by Vaz et al. (1992): "(...) it is difficult to measure the initial concentration (corresponding to the start of the sedimentation process $\mathrm{t}=0$ ) through beam attenuation. Therefore, the initial concentration was calculated from soil mass and solution volume. (...) Authors are now concerned with (...) developing studies involving (...) measurement of initial concentration through gamma attenuation". However, despite great improvement in the technique, no studies have as yet fully succeeded in this particular concern. Elias et al. (1999a) presented a method to measure the initial concentration at the beginning of the sedimentation process, $\mathrm{C}_{0}\left(\mathrm{~kg} \mathrm{~m}^{-3}\right)$, through beam attenuation, not from soil mass and solution volume. This method also eliminated the necessity of explicitly determining 
$C_{0}$, and also eliminated the necessity of measuring other variables: GRA coefficients of water and soil particles, $\mu_{\mathrm{w}}$ and $\mu_{\mathrm{p}}\left(\mathrm{m}^{2} \mathrm{~kg}^{-1}\right)$ respectively; soil particles density, $\mathrm{D}_{\mathrm{p}}\left(\mathrm{kg} \mathrm{m}^{-3}\right)$; and the path length, $\mathrm{X}$, which is the container internal dimension in the gamma beam direction. But the method presented a disadvantage: it required that sand was previously separated by sieving, whereas some other authors measured all soil fractions by gamma attenuation (Vaz et al. 1992, 1999; Oliveira et al. 1997; Naime et al. 2001).

The equation used by Vaz et al. (1992) to estimate particle concentration $\mathrm{C}\left(\mathrm{kg} \mathrm{m}^{-3}\right)$ at a time $\mathrm{t}$ is:

$$
C=\frac{\ln \left(I_{w} / I\right)}{X\left(\mu_{p}-\frac{\mu_{w} D_{w}}{D_{p}}\right)}
$$

and the relative particle concentration, $C^{\prime}$ (unitless) is

$$
\mathrm{C}^{\prime}=\mathrm{C} / \mathrm{CO}
$$

where $I_{w}\left(s^{-1}\right)$ and $I\left(s^{-1}\right)$ are the count intensities of the gamma-ray beams after crossing the absorbing medium composed of (i) dispersing solution and (ii) dispersing solution plus sedimenting soil particles, respectively; and $\mathrm{D}_{\mathrm{w}}\left(\mathrm{kg} \mathrm{m}^{-3}\right)$ is the water density.

In all the above-cited studies, the gamma beam is positioned in the horizontal direction, perpendicular to the sedimenting particles motion. If an additional measurement is made with the gamma beam in the vertical direction, over the same box containing the same sample, then $\mathrm{C}_{0}$ will remain constant during all the sedimentation process; consequently, it will be easy to measure $\mathrm{C}_{0}$ through beam attenuation. In accordance with Eq. [1], $\mathrm{C}_{0}$ will be:

$$
C_{0}=\frac{\ln \left(I_{w, v} / I_{C 0}\right)}{X_{h}\left(\mu_{p}-\frac{\mu_{w} D_{w}}{D_{p}}\right)}
$$


where $I_{c o}$ is the constant count intensity of the gamma-ray beam, now constant because the soil concentration in the vertical directions has no temporal variation, unlike I of Eq. [1]; $\mathrm{X}_{\mathrm{h}}$ is the container height; and I is similar to $I_{w}$, but measured in the vertical direction. Through Eq. [3], determination of $\mathrm{C}_{0}$ by GRA is achieved, as desired by Vaz et al. (1992), thus demonstrating one advantage of a vertical GRA system.

In addition, use of a vertical beam can simplify measurements even further: there is no actual need of explicitly determining $\mathrm{C}_{0}$. Dividing Eq. [1] by Eq. [3] yields:

$$
C^{\prime}=\frac{X_{h} \ln \left(I_{w} / I\right)}{X \ln \left(I_{w, v} / I_{C 0}\right)}
$$

If Eq. [4] is used, then explicit determination of $\mathrm{C}_{0}$ is not required. Only a rough estimate of $\mathrm{C}_{0}$ is necessary, to make sure that $\mathrm{C}_{0}$ is around 50 or $100 \mathrm{~kg} \mathrm{~m}^{-3}$, because such a concentration is necessary for application of Stoke's law to the sedimentation process. Hence there is not even the necessity of oven-drying the soil mass before weighing it. Also, determination of $\mu_{w}, \mu_{p}$ and $D_{p}$ is not required, which means a great simplification in PSA by GRA. Eq. [4] is similar to the equation presented by Elias et al. (1999a), with the advantage that Eq. [4] does not require sand to be previously separated by sieving.

But this procedure also brings two disadvantages. First, we note that $X_{h}$ will be larger than $X$; for example, $X_{h}=16 \mathrm{~cm}$ and $X=5 \mathrm{~cm}$ where the box dimensions in Vaz et al. (1999). As $X_{h}>X$, then $I_{w, v}<I_{w}$ and $\mathrm{I}_{\mathrm{C} 0}<\mathrm{I}$. Thus, precise determination of $\mathrm{I}_{\mathrm{w}, \mathrm{v}} \mathrm{I}_{\mathrm{co}}$ will require a relatively long photon-count time, because precision increases with the total photoncount. Second, a small systematic error would be introduced in Eq. [4], because the term $\left(\mu_{p}-\mu_{w} D_{w} / D_{p}\right)$ would not be exactly the same in Eqs. [1] and [3], as experimental values of attenuation coefficients are affected by the system geometry. As observed by Hopmans and Dane (1986, p. 1109): "Although theoretically the mass attenuation coefficients should be independent of position, light changes might occur due to changes in geometry of the source - soil column - detector configuration." 
Vaz et al. (1999) and Naime et al. (2001) developed an automated system for soil PSA by GRA. The system is not totally automated, because it requires previous, non-automated determination of $\mu_{\mathrm{p}}$ and $\mu_{\mathrm{w}}$. Eq. [4] enables the construction of a totally automated system. The vertical and horizontal gamma-ray measurements could be simultaneously carried out by two orthogonal beams; this would require two source-sample-detector systems. Alternatively, they could be carried out one at a time, by one single system capable of rotating, positioning itself along one of the two orthogonal directions at a time. However, implementation of such a system may considerably increase technological complexity and cost of the apparatus.

Eq. [4] is not altered if it is derived from the exact equations of Elias et al. (1999b) instead of deriving it from Eq. [1], which is an approximate equation. In fact, Eq. [4] is also exact.

\section{DETERMINATION OF SOIL GRA COEFFICIENTS}

Eq. [4] eliminates the need of calculating $\mu_{\mathrm{p}}$ in PSA by GRA, by using a vertical beam. However, there are many situations where determination of $\mu_{p}$ will continue to be necessary, and will not be eliminated by a vertical beam. For example, in studies of porosity, local water saturation and field capacity (Baytas and Akbal, 2002); water diffusivity (Barataud et al., 1999); or in simultaneous determination of soil water content and bulk density (Fahad, 1989; Mudahar and Sahota 1986). Also, some studies have been specifically aimed at determining $\mu_{p}$, for example, Appoloni and Rios (1994), and Singh et al. (1993). The ordinary way of calculating $\mu_{\mathrm{p}}$ is by packing sieved, oven-dry soil inside a box and making gamma attenuation measurements. This may cause a problem of soil-density variation along the box height, which is reduced by the experimenter skill at packing the soil. It may also be reduced by measuring the gamma beam intensity at different heights. In the particular case of Vaz et al. (1999, p. 404): "Photon count rates measured for 20 $s$ are recorded for five different heights from the bottom to the top (...)". We here suggest that a vertical beam would increase precision of $\mu_{\mathrm{p}}$ measurements, as the density variation is mainly along the container 
height, not along the horizontal direction. We may also speculate that shaking the dry soil sample, previous to the GRA measurement, may increase precision still further. Shaking would increase stratification and heterogeneity along the vertical direction; but it would possibly decrease heterogeneity along horizontal planes perpendicular to the vertical direction. Moreover, $\mu_{\mathrm{p}}$ could be measured by adding solution to the soil sample and using the automated apparatus for soil PSA by GRA described above, which includes a mixer. Then, $\mu_{\mathrm{p}}$ could be measured from observing that Eq. [3] can be solved for $\mu_{\mathrm{p}}$ :

$$
\mu_{p}=\frac{\ln \left(I_{w^{\prime}, v} / I_{C 0}\right)}{C_{0} X_{h}}+\frac{\mu_{w} D_{w}}{D_{p}} .
$$

Application of Eq. [5] requires that $\mathrm{C}_{0}$ is calculated from soil mass and solution volume. Measuring $\mu_{\mathrm{p}}$ in this novel way, by Eq. [5], should eliminate heterogeneity on horizontal planes, as the sedimenting soil suspension is homogenized by a mixer. For such applications, the optimal value of soil concentration (for best precision) may be greater than the usual 50 or $100 \mathrm{~kg} \mathrm{~m}^{-3}$ used in soil PSA. In PSA, concentration has to be made low so that Stoke's law is applicable. Such a constraint would not exist in $\mu_{\mathrm{p}}$ measurements, as Stoke's law would not be used.

There is, however, a disadvantage to this procedure. For a high photon-energy gamma-ray source, such as ${ }^{137} \mathrm{Cs}$, heavy shielding is required, so that it would be less practical to place source - sample - detector along a vertical direction. Even for a low photon-energy gamma-source, such as ${ }^{24 l} \mathrm{Am}$, the detector may have heavy shielding, even if the source does not; it depends on the GRA system used. The problem may be reduced by positioning the source above the detector, if the source is the lightest component, or the other way round, if the detector is the lightest component.

The method of Elias et al. (1999a) could, in principle, be also used to determine $\mu_{\mathrm{p}}$ through Eq. [5], but in that method there is the disadvantage that the maximum photon-count time permitted to measure $\mathrm{I}_{\mathrm{c} 0}$ was $40 \mathrm{~s}$, whereas there is no counting time limit in the present method; this is in addition to the already mentioned disadvantage of separating the sand by sieving. 
Calibration constants have also been used to deal with the problem of irregularities along a soil column (Hopmans and Dane, 1986; Nofziger and Swartzendruber, 1974). A future study may attempt to relate calibration constants with the ideas here presented.

\section{CONCLUSION}

Two possible applications of a vertical GRA system have been shown here: PSA, through Eq. [4], and measurements of GRA coefficients of soils, through Eq. [5]. We have also presented some qualitative considerations on precision and accuracy of such applications. We suggest further theoretical and experimental research to confirm the theory presented here, including comprehensive error-analysis. We also suggest that future studies consider the possibility of using a vertical beam whenever the gravitational field may affect measurements; this may be applicable to other situations besides the two studied here.

\section{REFERENCES}

APPOLONI, C.R.; RIOS, E.A., 1994. Mass Attenuation Coefficients of Brazilian Soils in the Range 10-1450 keV. Appl. Radiat. Isot., 45:287-291.

BARATAUD, F.; MOYNE, C.; STEMMELEN, D., 1999. Measurement of Soil Water Diffusivity of na Undisturbed Forest Soil Using DualEnergy Gamma Radiation Technique. Soil Science, 164:493-502. BAYTAS, A.F.; AKBAL, S., 1999. Determinaation of Soil Parameters by Gamma-Ray Transmission. Radiation Measurements, 35:17-21. ELIAS, E.A., 2004. A Simplified Analytical Procedure for Soil ParticleSize Analysis by Gamma-Ray Attenuation. Comput. Eletron. Agric., 42(3): 181-184.

ELIAS, E.A.; BACCHI, O.O.S.; REICHARDT, K., 1999a. Alternative Soil Particle-Size Analysis by Gamma-Ray Attenuation. Soil Tillage Res., 52(1/2):121-123.

ELIAS, E.A.; BACCHI, O.O.S.; REICHARDT, K., 1999b. Exact Equations for Soil Particle-Size Analysis by Gamma-Ray Attenuation. Scientia 
Agricola., 56(1):93-96. (Available from World Wide Web: $<\underline{\text { http:// }}$ www.scielo.br/scielo/php?script $=$ sci arttext \&pid=S010390161999000100014\&Ing=en\&nrm=iso $>$ ) (Verified 23 March 2003). FAHAD, A.A., 1989. A Computer-Controlled Dual-Gamma Scanner for Measurement of Soil Water Content and Bulk Density. Appl. Radiat. Isot., 40:340-342.

HOPMANS, J.W.; DANE, J.H., 1986. Calibration of a Dual-Energy Gamma Radiation System for Multiple Point Measurements in a Soil. Water Res. Res., 22(7):1109-1114.

KARSTEN, J.H.M.; KOTZÉ, W.A.G., 1984. Soil Particle-Size Analysis with the Gamma Attenuation Technique. Comm. In Soil Science and Plant Analysis., 15(6):731-739.

MUDAHAR, G.S.; SAHOTA, 1986. A New Method for Simultaneous Measurement of Soil Bulk Density and Water Content. Appl. Radiat. Isot., 37:563-565.

NAIME, J.M.; VAZ, C.M.P.; MACEDO, A., 2001. Automed Soil ParticleSize Analyser based on Gamma-Ray Attenuation. Comp. Eletro. Agric., 31:295-304.

NOFZIGER, D.L.; SWARTZENDRUBER, D., 1974. Material Content of Binary Physical Mixtures as Measured with a Dual-Energy Bean of Gamma-Ray. J. Appl. Phys., 45:5443-5449.

OLIVEIRA, J.C.M.; VAZ, C.P.M.; REICHARDT, K.; SWARTZENDRUBER, D., 1997. Improved Soil Particle-Size Analysis by Gamma-Ray Attenuation. Soil Sci. Soc. Am. J., 61:23-26.

ROSS, P.R., 1959. Particle-Size Analysis by Gamma-Ray Absorption. Analytical Chemistry, 31(3):337-339.

SINGH, M.; BRAR, G.S.; MUDAHAR, G.S., 1993. Attenuation Coefficients of a Soil as a Function of Particle-Size. Indian J. of Pure \& Appl. Physics, 31:593-594.

VAZ, C.P.M.; OLIVEIRA, J.C.M.; REICHARDT, K.; CRESTANA, S.; CRUVINEL, P.E.; BACCHI, O.O.S., 1992. Soil Mechanical Analysis Through Gamma-Ray Attenuation. Soil Technol., 5:319-325.

VAZ, C.P.M.; NAIME, J.M.; MACEDO, A., 1999. Soil Particle-Size Fractions Determined by Gamma-Ray Attenuation. Soil Sci., 164(6):403-410. 